\title{
The Effect of Inhibitors of Renal Transport on the Small Intestine *
}

\author{
Henry J. Binder, $\dagger$ Leonard A. Katz, Richard P. Spencer, and \\ How ARD M. SPIRO $\$$ \\ (From the Departments of Internal Medicine and Radiology [Nuclear Medicine], Yale \\ University School of Medicine, New Haven, Conn.)
}

In the genetically determined disorders cystinuria and Hartnup disease, amino acid transport defects are present in both the small intestine and the kidney $(2-4)$. It would seem logical that agents which alter kidney function may also affect the transporting ability of the small intestine. We have therefore studied the effect on intestinal transport (by means of in vitro intestinal preparations) of some of the drugs that inhibit renal tubular transport.

\section{Methods}

Everted gut sacs were made from the small intestine of male golden hamsters weighing between 80 and $130 \mathrm{~g}$ (5). The nonfasting animal was killed by a blow on the head. The small intestine was then isolated, washed in situ with $\mathrm{pH} 7.4 \mathrm{Krebs}$ bicarbonate buffer, and removed by stripping off the mesentery. It was then everted, and three segments each weighing approximately $600 \mathrm{mg}$ were constructed from the entire length of the bowel. The nonelectrolyte whose transport was to be studied was placed at varying concentrations in the buffer, and $1 \mathrm{ml}$ of this fluid was placed inside the sac. The sac was then placed in an Erlenmeyer flask with $5 \mathrm{ml}$ of buffer containing the nonelectrolyte at an identical concentration. Potential inhibitors at several concentrations were added to the buffer as indicated. After being gassed with $95 \%$ $\mathrm{O}_{2}$ and $5 \% \mathrm{CO}_{2}$, the flasks were stoppered and placed in an oscillating water bath kept at $37^{\circ} \mathrm{C}$ and 50 vibrations per minute for 1 hour. Portions of the serosal and mucosal fluids were centrifuged and then analyzed for radioactivity in a liquid scintillation spectrometer. ${ }^{1}$ Sacs were blotted and weighed.

* Submitted for publication May 26, 1966; accepted August 24, 1966.

Supported in part by grants AM 98870, CA 06519, and AM 09429 from the U. S. Public Health Service and a grant-in-aid from the Connecticut Heart Association.

A preliminary report has appeared in abstract form (1).

† Special Fellow of the National Institute of Arthritis and Metabolic Diseases (1F3 AM-28399).

$\ddagger$ Address requests for reprints to Dr. Howard $M$. Spiro, Yale University School of Medicine, 333 Cedar St., New Haven, Conn. 06504.

1 Picker Nuclear Corp., White Plains, N. Y.
The radioactively labeled materials $\mathrm{L}-1 \mathrm{ysine}{ }^{14} \mathrm{C}$ (UL), ${ }^{2}$ methyl-L-methionine- $-{ }^{14} \mathrm{C},{ }^{2} 2$-uracil- ${ }^{14} \mathrm{C},{ }^{2}$ glucose- ${ }^{14} \mathrm{C}$ (UL), ${ }^{2}$ and ${ }^{22} \mathrm{Na},{ }^{2}$ as well as $\mathrm{L}$-lysine monohydrochloride, ${ }^{3}$ were obtained commercially. Ethacrynic acid [2,3-dichloro-4(2 methylenebutyryl)-phenoxyacetic acid], 4 probenecid, 4 and chlorothiazide ${ }^{4}$ were used as the pure powders.

Krebs bicarbonate buffer ( $\mathrm{pH} 7.4$; sodium, $147 \mathrm{mEq}$ per L; chloride, $127 \mathrm{mEq}$ per $\mathrm{L}$; $\mathrm{H}_{2} \mathrm{PO}_{4}, 1.1 \mathrm{mEq}$ per L; and $\mathrm{HCO}_{3}^{-}, 25 \mathrm{mEq}$ per $\mathrm{L}$ ) with a potassium concentration of $6.1 \mathrm{mEq}$ per $\mathrm{L}$ was used in all experiments unless otherwise indicated. In some experiments buffer was used with a potassium concentration of $16.1 \mathrm{mEq}$ per $\mathrm{L}$ and a sodium concentration of $135 \mathrm{mEq}$ per $\mathrm{L}$; this is referred to as "high potassium" buffer. In other experiments potassium was removed from the buffer, and the sodium concentration was increased to $152 \mathrm{mEq}$ per $\mathrm{L}$; this is referred to as "potassium-free" buffer. Anion concentrations remained unchanged in all buffers.

Nonelectrolyte transport. Nonelectrolyte transport was expressed as the ratio of mucosal-to-serosal concentration. Per cent inhibition was determined by comparing the increase in counts in the serosal medium per gram of wet tissue weight to that of an equal number of control sacs. In each experiment the absorption of six sacs from two animals in the presence of a potential inhibitor was compared to that of an equal number of control sacs. Each result represents at least two separate experiments.

Water transport. Net movement of water into the serosal compartment was determined gravimetrically. All weighings were performed in an identical fashion. The initial weight of the serosal fluid was determined before incubation by subtracting the weight of the empty sac from the weight of the filled sac. The weight of the serosal volume after incubation was determined by weighing the filled sac and reweighing after thorough drainage. The difference between these two weights was a measure of the net change in the serosal water compartment. To express this as milligram per milligram of dry tissue weight, we dried the tissue at $105^{\circ} \mathrm{C}$ overnight and reweighed it.

Net sodium movement. ${ }^{22} \mathrm{Na}$ was utilized in an estimate of net sodium movement by subtracting the initial total counts in the serosal compartment from the final total counts in the serosal compartment. Total counts

2 New England Nuclear Corp., Boston, Mass.

3 Nutritional Biochemicals Corp., Cleveland, Ohio.

4 Kindly supplied by Merck Sharp \& Dohme Research Laboratories, West Point, $\mathrm{Pa}$. 
TABLE I

Inhibition by $5 \mathrm{mM}$ ethacrynic acid of nonelectrolyte absorption against a concentration gradient by the hamster everted small intestine

\begin{tabular}{llll}
\hline \hline & Control & Ethacrynic acid & $\mathrm{p}$ \\
\hline $5 \times 10^{-6} \mathrm{M}$ L-methionine & $6.40 \pm 2.56^{*}(12)$ & $1.37 \pm 0.42(11)$ & $<0.001$ \\
$10^{-4} \mathrm{M}$ L-lysine & $3.39 \pm 1.78(12)$ & $1.43 \pm 0.26(12)$ & $<0.001$ \\
$10^{-3} \mathrm{M}$ glucose & $8.36 \pm 3.40(12)$ & $1.36 \pm 0.19(12)$ & $<0.001$ \\
$10^{-5} \mathrm{M}$ uracil & $3.49 \pm 1.32(12)$ & $1.25 \pm 0.23(12)$ & $<0.001$ \\
\hline
\end{tabular}

* Mean of mucosal/serosal concentration \pm standard deviation. Number in parentheses represents number of sacs.

in the serosal fluid were calculated initially from the known volume and the counts per unit volume. The total counts in the serosal compartment after incubation were determined by counting the entire inside volume in an automatic gamma counter. 5 The per cent increase in total counts at the end of the incubation period per milligram of dry tissue weight represented net movement of ${ }^{2} \mathrm{Na}$.

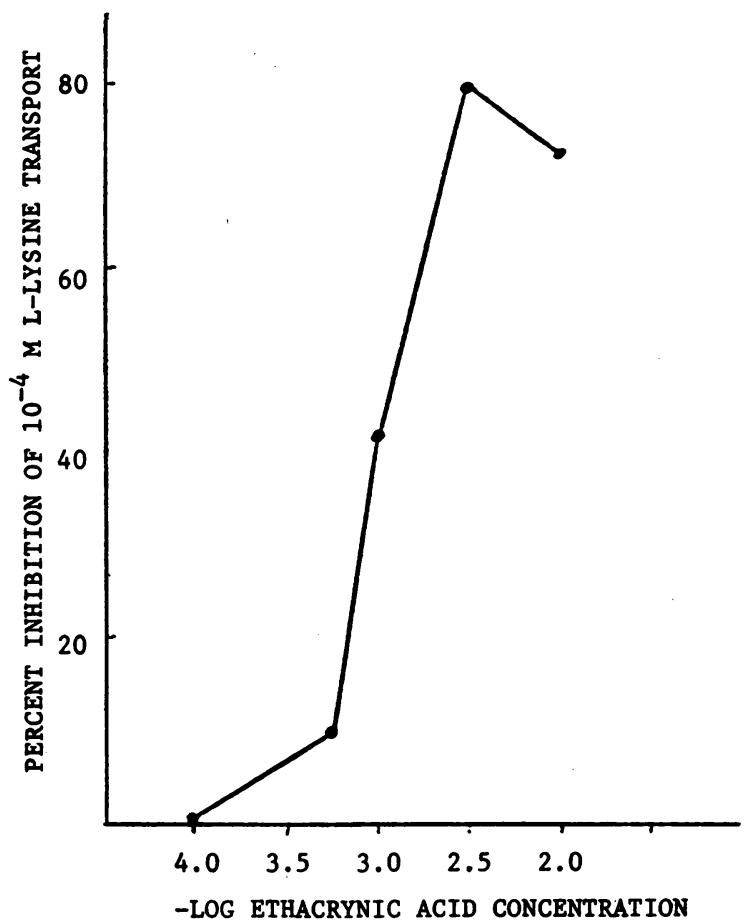

Fig. 1. EFfect OF VARYing CONCENTRATIONS OF ETHACRYNIC ACID ON AMINO ACID ABSORPTION IN THE HAMSTER SMALL INTESTINE. The inhibition of the transport of $10^{-4} \mathrm{M}$ L-lysine by ethacrynic acid was dose related between $0.5 \mathrm{mM}$ and $5 \mathrm{mM}$ concentration. Ten $\mathrm{mM}$ ethacrynic acid did not cause any further inhibition than 5 $\mathrm{mM}$. The incubation procedure was as described in the text, with the concentration of ethacrynic acid being varied. Each point represents the mean of six sacs. The standard deviations were approximately $25 \%$ of the mean values.

\footnotetext{
5 Picker Nuclear Corp., White Plains, N. Y.
}

Student's $t$ test was applied by standard statistical methods (6).

\section{Results}

Ethacrynic acid. The absorption of $5 \times 10^{-6} \mathrm{M}$ L-methionine, $10^{-4} \mathrm{M}$ L-lysine, $10^{-3} \mathrm{M}$ glucose, and $10^{-5} \mathrm{M}$ uracil by the hamster small intestine was markedly inhibited by $5 \mathrm{mM}$ ethacrynic acid (Table I).

The effect of varying the concentration of ethacrynic acid on the inhibition of absorption of $10^{-4}$ M L-lysine was determined (Figure 1). Ethacrynic acid at $0.1 \mathrm{mM}$ and $0.5 \mathrm{mM}$ concentrations failed to inhibit absorption, but maximal inhibition was obtained at a $5 \mathrm{mM}$ concentration. The inhibition of L-lysine absorption by $5 \mathrm{mM}$ ethacrynic acid was similar at $10^{-3} \mathrm{M}, 5 \times 10^{-4} \mathrm{M}$, and $10^{-4}$ $M$ concentrations of amino acid (Table II).

Water and ${ }^{22} \mathrm{Na}$ absorption were also markedly impaired in the presence of $5 \mathrm{mM}$ ethacrynic acid (Tables III and IV). Inhibition of water absorption was also dependent on the dosage of ethacrynic acid. One-tenth $\mathrm{mM}$ ethacrynic acid had no effect; $0.5 \mathrm{mM}$ acid significantly inhibited water absorption (Table III).

A study of the importance of the concentration of potassium in the medium was made. At 0.5 $\mathrm{mM}$ ethacrynic acid, there was no effect on L-lysine absorption with a potassium concentration of 6.1 $\mathrm{mEq}$ per $\mathrm{L}$ (Figure 1). This is in contrast to a significant inhibition in a potassium-free medium.

TABLE II

Inhibition of absorption of varying concentrations of L-lysine by $5 \mathrm{mM}$ ethacrynic acid in the hamster small intestine

\begin{tabular}{lc}
\hline & $\begin{array}{c}\text { \% transport } \\
\text { of controls }\end{array}$ \\
\hline $10^{-3}$ M L-lysine & 16 \\
$5 \times 10^{-4}$ M L-lysine & 12 \\
$10^{-4}$ M L-lysine & 19 \\
\hline
\end{tabular}


TABLE III

Translocation of water across the hamster everted small intestine as modified by ethacrynic acid*

\begin{tabular}{lcc}
\hline \hline & Water uptake† & $\mathrm{p}$ \\
\hline Control & $4.89 \pm 2.82 \ddagger(15)$ & \\
Ethacrynic acid & $-0.74 \pm 0.89(6)$ & $<0.001$ \\
$5 \mathrm{mM}$ & $-0.28 \pm 0.96(5)$ & $<0.01$ \\
$1 \mathrm{mM}$ & $0.25 \pm 1.20(9)$ & $<0.01$ \\
$0.5 \mathrm{mM}$ & $2.66 \pm 1.74(5)$ & $\mathrm{NS}$ \\
$0.1 \mathrm{mM}$ & &
\end{tabular}

* Each sac filled with $0.5 \mathrm{ml}$ Krebs-bicarbonate buffer containing $12.2 \mathrm{mM}$ glucose was placed in $7.5 \mathrm{ml}$ buffer. Each flask was incubated at $37^{\circ} \mathrm{C}$ for 60 minutes after gassing with $95 \% \mathrm{O}_{2}-5 \% \mathrm{CO}_{2}$.

$\dagger$ Expressed as the increase in the serosal compartment (in milligrams) per milligram dry tissue weight.

$\ddagger$ Mean \pm standard deviation. Number in parentheses represents number of sacs.

The mucosal-serosal concentration ratio in a potassium-free buffer without ethacrynic acid was $3.72 \pm 0.91$ (not significantly different from that in $6.1 \mathrm{mEq}$ per $\mathrm{L}$ potassium medium shown in Table $\mathrm{I}$ ), and in the presence of $0.5 \mathrm{mM}$ ethacrynic acid it was $2.34 \pm 0.52(\mathrm{p}<0.001)$. An increased potassium concentration decreased the inhibition of $10^{-4} \mathrm{M}$ L-lysine absorption by $5 \mathrm{mM}$ ethacrynic acid; in Krebs-bicarbonate buffer ( $\mathrm{K}=$ $6.1 \mathrm{mEq}$ per L), L-lysine absorption was inhibited $80 \%$ by $5 \mathrm{mM}$ ethacrynic acid, but in a high potassium buffer the inhibition by $5 \mathrm{mM}$ ethacrynic acid was reduced to $62 \%$.

Chlorothiazide. Two $\mathrm{mM}$ chlorothiazide did not significantly inhibit intestinal transport of L-methionine, L-lysine, glucose, or uracil (Table V). Water and ${ }^{22} \mathrm{Na}$ absorption were impaired in the presence of $2 \mathrm{mM}$ chlorothiazide (Tables IV and VI).

Probenecid. The intestinal transport of L-methionine and L-lysine was significantly inhibited by

TABLE IV

Net absorption of ${ }^{22} \mathrm{Na}$ across the everted hamster small intestine as modified by ethacrynic acid, chlorothiazide, and probenecid*

\begin{tabular}{lrl}
\hline \hline & Net ${ }^{22 \mathrm{Na}}$ absorptiont & $\mathrm{p}$ \\
\hline Control (9) & $0.42 \pm 0.40 \ddagger$ & \\
Ethacrynic acid 5 mM (6) & $-0.45 \pm 0.14$ & $<0.001$ \\
Probenecid 5 mM (7) & $0.24 \pm 0.27$ & $\mathrm{NS}$ \\
Cblorothiazide 2 mM (5) & $-0.11 \pm 0.16$ & $<0.02$ \\
\hline
\end{tabular}

* Details of incubation procedure are as described in Table III except that an equal amount of ${ }^{22} \mathrm{Na}$ was added to both mucosal and serosal media.

$\dagger$ Net ${ }^{22} \mathrm{Na}$ movement expressed as increase in counts in total serosal medium at the end of the incubation period per initial total counts in serosal medium per milligram dry tissue weight.

$\ddagger$ Mean \pm standard deviation.
TABLE V

Nonelectrolyte absorption across the everted hamster small intestine in the presence of $2 \mathrm{mM}$ chlorothiazide*

\begin{tabular}{lcccc}
\hline & Control & Chlorothiazide & p \\
\hline $5 \times 10^{-6}$ M L-methionine & $5.49 \pm 0.72 *(24)$ & $5.01 \pm 1.85(24)$ & NS \\
$10^{-4}$ M L-lysine & $2.96 \pm 1.29(17)$ & $3.24 \pm 1.28(18)$ & NS \\
$10^{-8}$ M glucose & $3.29 \pm 2.33(18)$ & $3.46 \pm 2.32(18)$ & NS \\
$10^{-5}$ M uracil & $3.84 \pm 2.19(12)$ & $4.96 \pm 1.09(11)$ & NS
\end{tabular}

* Mean of mucosal/serosal concentration \pm standard deviation. Number in parentheses represents number of sacs.

$5 \mathrm{mM}$ probenecid (Table VII). The inhibition of L-lysine and L-methionine transport by probenecid was dose related (Table VIII). Water and ${ }^{22} \mathrm{Na}$ absorption in the hamster small intestine was not impaired by the presence of $5 \mathrm{mM}$ probenecid (Tables IV and VI). The transport of glucose and uracil was decreased, but not significantly, by $5 \mathrm{mM}$ probenecid.

\section{Discussion}

Ethacrynic acid is a potent diuretic agent that inhibits sodium and water reabsorption in the ascending limb of the loop of Henle (7). Ethacrynic acid has been demonstrated to inhibit renal sodium-potassium-dependent ATPase $(8,9)$ and to inhibit both sodium efflux from erythrocytes $(10,11)$ and sodium movement across the toad bladder (12).

In the present study, ethacrynic acid also inhibited transport of sodium in sacs made from the small intestine of the golden hamster. The occurrence of this inhibition appears straightforward, although the mechanism (whether due to inhibition of ATPase or another phenomenon) is uncertain. Ouabain and oligomycin, drugs that inhibit sodium-potassium ATPase and the "sodium pump," also inhibit amino acid and sugar transport $(13,14)$. Ethacrynic acid inhibited nonelectrolyte transport in a dose-related manner, prob-

TABLE VI

Net absorption of water as modified by chlorothiazide and probenecid across the everted hamster small intestine*

\begin{tabular}{llc}
\hline \hline & Net water uptake & p \\
\hline Controls & $4.89 \pm 2.82+(15)$ & \\
Probenecid $5 \mathrm{mM}$ & $3.62 \pm 2.31(7)$ & NS \\
Chlorothiazide $2 \mathrm{mM}$ & $0.79 \pm 0.75(14)$ & $<0.001$ \\
\hline
\end{tabular}

* See Table III for details of incubation procedure.

$\dagger$ Mean \pm standard deviation. Number in parentheses represents number of sacs. 
TABLE VII

Nonelectrolyte absorption across the everted hamster small intestine in the presence of $5 \mathrm{mM}$ probenecid*

\begin{tabular}{lccc}
\hline \hline & Control & Probenecid & p \\
\hline $5 \times 10^{-6}$ M L-methionine & $5.77 \pm 3.28^{*}(12)$ & $2.66 \pm 1.26(12)$ & $<0.01$ \\
$10^{-4} \mathrm{M}$ L-lysine & $2.86 \pm 1.10(12)$ & $1.79 \pm 0.23(12)$ & $<0.01$ \\
$10^{-3} \mathrm{M}$ glucose & $4.59 \pm 2.79(23)$ & $3.26 \pm 1.68(24)$ & NS \\
$10^{-5}$ M uracil & $3.77 \pm 2.18(17)$ & $3.03 \pm 1.51(18)$ & NS \\
\hline
\end{tabular}

* Mean of mucosal/serosal concentration \pm standard deviation. Number in parentheses represents number of sacs.

ably secondary to the inhibition of sodium transport (we have preliminary data that the inhibition is noncompetitive, since it is not overcome by increasing the concentration of the nonelectrolyte). Whether ethacrynic acid also acts as a metabolic inhibitor in the intestine is unknown. After a $100-\mathrm{mg}$ dose of ethacrynic acid, if the compound were dissolved in $5 \mathrm{~L}$ of blood, the concentration would be approximately $10^{-4}$ mole per $\mathrm{L}$. The actual quantity bound to the kidney or gut in vivo is as yet unknown. The action of ethacrynic acid is clearly related to the potassium concentration of the medium. At low potassium concentrations ethacrynic acid is more effective as an inhibitor; its action is decreased by increasing the potassium concentration. Similar results are seen in studies of sodium efflux in human erythrocytes (10). As a possible explanation of this phenomenon Hoffman has suggested that potassium is bound to the site of ethacrynic acid action (15).

Chlorothiazide probably inhibits reabsorption of sodium in the distal tubules and also interferes with the transport of uric acid (16). However, its ability to inhibit ATPase has not been demonstrated (8). Two $\mathrm{mM}$ chlorothiazide and $0.5 \mathrm{mM}$ ethacrynic acid fail to inhibit nonelectrolyte transport, but do inhibit water transport. This apparent dissociation of sodium transport as reflected by water transport and amino acid transport may be related to the linear relationship between sodium and amino acid transport at sodium concentrations below $100 \mathrm{mEq}$ per L. Two $\mathrm{mM}$ chlorothiazide and $0.5 \mathrm{mM}$ ethacrynic acid may not inhibit sodium transport sufficiently to inhibit amino acid transport.

Probenecid is an established inhibitor of renal tubular transport that can block either reabsorption or secretion of several organic compounds such as penicillin and uric acid (17). Therefore, that it can also inhibit intestinal transport is not unexpected. Its action on amino acid transport seems to be specific, since probenecid does not inhibit water and sodium transport.

In the present study we have demonstrated the ability of several drugs, whose primary and perhaps sole function had been thought to be on the renal tubules, to inhibit intestinal absorption. This strengthens the evidence that there are functional similarities in the transport systems in the kidney and the small intestine. Morphologically the kidney and the small intestine have at least one similarity. Microvilli are characteristic of the small intestine and many other absorptive surfaces and are also found in the proximal tubules of the kidney (18). More recently, the site of amino acid reabsorption in the kidney has also been localized to the proximal tubules (19). A further similarity is that defects in amino acid transport systems have been found in the small intestine as well as in the kidney in the genetically determined diseases, cystinuria and Hartnup disease (2-4).

These observations may have clinical pertinence to the cachexia seen in some patients with chronic congestive heart failure. In addition to the malabsorption usually attributed to tissue anoxia (20), the cardiorenal drugs might also contribute to cardiac cachexia by inhibiting intestinal absorption. The diarrhea that infrequently occurs during ethacrynic acid therapy (21-23) may be a consequence of inhibition of ATPase activity and sodium transport as has been postulated for the cathartic action of cascara and other vegetable cathartics (24) and in the diarrhea of cholera (25).

TABLE VIII

Inhibition of amino acid absorption by varying concentrations of probenecid in the hamster small intestine

\begin{tabular}{ccc}
\hline \hline & \multicolumn{2}{c}{$\begin{array}{c}\% \text { transport } \\
\text { of controls }\end{array}$} \\
\cline { 2 - 3 } & L-Lysine & L-Methionine \\
\hline Probenecid $0.5 \mathrm{mM}$ & 113 & 99 \\
Probenecid $5.0 \mathrm{mM}$ & 62 & 47 \\
\hline
\end{tabular}




\section{Summary}

Nonelectrolyte transport has been studied in everted hamster small intestinal sacs. Ethacrynic acid, a diuretic agent, significantly inhibited amino acid, glucose, and pyrimidine transport. Water and sodium transport was impaired by both ethacrynic acid and chlorothiazide. Probenecid inhibited amino acid transport only.

We suggest that these observations provide further evidence of functional similarities between the kidney and the small intestine. The relationship of cardiorenal drugs to intestinal absorption was discussed.

\section{Acknowledgments}

The authors are grateful to Mrs. Marigrace Boyer for invaluable expert technical assistance, to Dr. Franklin Epstein for reviewing the manuscript, and to Dr. Charles Wilkinson of Merck Sharp \& Dohme Research Laboratories for the generous supply of ethacrynic acid, probenecid, and chlorothiazide.

\section{References}

1. Binder, H. J., H. M. Spiro, and R. P. Spencer. Inhibition of intestinal absorption by agents that affect the kidney (abstract). J. clin. Invest. 1966, 45, 987.

2. McCarthy, C. F., J. L. Borland, Jr., H. J. Lynch, Jr., E. E. Owen, and M. P. Tyor. Defective uptake of basic amino acids and L-cystine by intestinal mucosa of patients with cystinuria. J. clin. Invest. 1964, 43, 1518.

3. Thier, S. O., S. Segal, M. Fox, A. Blair, and L. E. Rosenberg. Cystinuria: defective intestinal transport of dibasic amino acids and cystine. J. clin. Invest. $1965,44,442$.

4. Milne, M. D., M. A. Crawford, C. B. Girão, and L. W. Loughridge. The metabolic disorder in Hartnup disease. Quart. J. Med. 1960, 29, 407.

5. Wilson, T. H., and G. Wiseman. The use of sacs of everted small intestine for the study of the transference of substances from the mucosal to the serosal surface. J. Physiol. (Lond.) 1954, 123, 116.

6. Snedecor, G. W. Statistical Methods Applied to Experiments in Agriculture and Biology. Ames, Iowa State University Press, 1956, p. 77.

7. Goldberg, M., D. K. McCurdy, E. L. Foltz, and L. W. Bluemle, Jr. Effects of ethacrynic acid (a new saluretic agent) on renal diluting and concentrating mechanisms: evidence for site of action in the loop of Henle. J. clin. Invest. 1964, 43, 201.

8. Duggan, D. E., and R. M. Noll. Effects of ethacrynic acid and cardiac glycosides upon a membrane adenosinetriphosphatase of renal cortex. Arch. Biochem. 1965, 109, 388.
9. Hook, J. B., and H. E. Williamson. Lack of correlation between natriuretic activity and inhibition of renal Na-K-activated ATPase. Proc. Soc. exp. Biol. (N. Y.) 1965, 120, 358.

10. Hoffman, J. F., and F. M. Kregenow. Characterization of new energy-dependent cation transport processes in red blood cells. Ann. N. Y. Acad. Sci. 1966, 137, 566.

11. Sachs, J. R., and L. G. Welt. The influence of diuretic agents on the cation transport system in the human red blood cells (abstract). Clin. Res. 1966, 14, 109.

12. Lipson, S., B. M. Brenner, and R. M. Hayes. The effect of ethacrynic acid on sodium transport in the toad bladder (abstract). Clin. Res. 1965, 13, 556.

13. Csáky, T. Z. Effect of cardioactive steroids on the active transport of non-electrolytes. Biochim. biophys. Acta (Amst.) 1963, 74, 160.

14. Binder, H. J., R. P. Spencer, H. M. Spiro, F. Vishno, and $M$. Boyer. Modification of intestinal amino acid transport by hormones, antimetabolites and analogues. Fed. Proc. 1966, 25, 639.

15. Hoffman, J. F. Personal communication.

16. Earley, L. E., and J. Orloff. Thiazide diuretics. Ann. Rev. Med. 1964, 15, 149.

17. Brazeau, P. Inhibitors of renal tubular transport of organic compounds in The Pharmacological Basis of Therapeutics, 3rd ed., L. S. Goodman and A. Gilman, Eds. New York, MacMillan, 1965, p. 871.

18. Rhodin, J. Electron microscopy of the kidney. Amer. J. Med. 1958, 24, 661.

19. Wright, L. A., and T. F. Nicholson. The proximal tubular handling of amino acids and other Ninhydrin-positive substances. Canad. J. Physiol. Pharmacol. 1966, 44, 183.

20. Pittman, J. G., and P. Cohen. The pathogenesis of cardiac cachexia. New Eng1. J. Med. 1964, 271, 403, 453.

21. Hagedorn, C. W., A. A. Kaplan, and W. H. Hulet. Prolonged administration of ethacrynic acid in patients with chronic renal disease. New Engl. J. Med. 1965, 272, 1152.

22. Brest, A. N., G. Onesti, R. Seller, O. Ramirez, C. Heider, and J. H. Moyer. Pharmacodynamic effects of a new diuretic drug, ethacrynic acid. Amer. J. Cardiol. 1965, 16, 99.

23. Hilton, J. G., and E. Kessler. Toxic reactions to ethacrynic acid, a new oral diuretic. J. New Drugs 1964, 4, 93.

24. Phillips, R. A., A. H. G. Love, T. G. Mitchell, and E. M. Neptune, Jr. Cathartics and the sodium pump. Nature (Lond.) 1965, 206, 1367.

25. Hirschhorn, N., J. R. Saha, and I. H. Rosenberg. Sodium-potassium-activated ATPase in human small intestine: reversible depression in cholera and acute gastroenteritis (abstract). J. clin. Invest. 1966, 45, 1023. 